\title{
Evaluation of Syringe Feeding Compared to Bottle Feeding for the Transition from Gavage Feeding to Oral Feeding in Preterm Infants
}

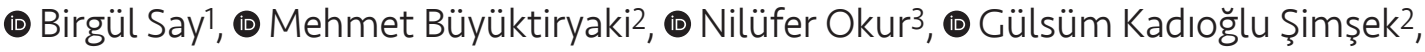 \\ (1) Fuat Emre Canpolat2, (1) Nurdan Uraş22, (1) Şerife Suna Oğuz² \\ 1 University of Health Sciences, Derince Training and Research Hospital, Clinic of Neonatology, Kocaeli, Turkey \\ 2University of Health Sciences, Ankara Dr. Zekai Tahir Burak Women's Health Training and Research Hospital, Clinic of Neonatology, \\ Ankara, Turkey \\ ${ }^{3}$ Dicle University Faculty of Medicine, Department of Neonatology, Diyarbakır, Turkey
}

\begin{abstract}
Aim: Syringe feeding is a good alternative to a nursing supplementer when breastfeeding is not possible.

Materials and Methods: This study was conducted at a level 2 neonatal intensive care unit in the Zekai Tahir Burak Maternity Teaching Hospital in a comparative and descriptive clinical study pattern. The study was carried out with 47 preterm infants in a syringe-fed group (SC) and 56 preterm infants in a bottle-fed group (BG). Primary outcomes were time of transition from gavage feeding to full oral feeding time of transition from tube to breastfeeding, and hospitalization time. Secondary outcomes were body weight at discharge (g), daily body weight gain (g/days) and gastro-intestinal intolerance symptoms during the transition period.

Results: Mean gestational ages were $29.82 \pm 2.03$ vs $28.18 \pm 1.56$ weeks $(p=0.24)$ and mean birth weights were $1,150.31 \pm 232.29 \mathrm{vs} 1,016.87 \pm 186.64$ $g(p=0.72)$ in the SG and BC groups, respectively. One hundred and three infants receiving gavage feeding with gestational ages ranging from 26 to 32 weeks were evaluated for full oral feeding start time. Syringe-fed preterm infants had a mean of $40.45 \pm 19.50$ days and bottle-fed infants had a mean of $53.81 \pm 16.97$ days $(p>0.05)$. The time to transition to breastfeeding $(42.54 \pm 21.21$ days) and time to discharge ( $54.48 \pm 26.92$ days) in the SC was significantly shorter compared to the BG $(50.45 \pm 15.95,67.21 \pm 22.07$, respectively) $(p<0.05)$.

Conclusion: We found that preterm infants for whom feeding with a syringe was used as a reinforcement in addition to orogastric feeding switched to full breastfeeding in a shorter time compared to infants who were fed by bottle. From these results, we recommend syringe feeding as a transitional method prior to breastfeeding for preterm infants during hospitalization.

Keywords: Preterm infants, exclusive breastfeeding, feeding method
\end{abstract}

\section{Introduction}

The physiological limitations of preterm infants less than 32 weeks gestational age make oral feeding difficult. Gavage feeding is the most common and preferred method to initiate enteral feeding in preterm infants (1). Prolonged use of gavage feeding is common in preterm infants who have not yet improved suck, swallow and breathing coordination. However, transition from gavage feeding to breastfeeding or bottle feeding is frequently difficult, resulting in prolonged hospital stays. In addition, research indicates that adverse 
outcomes related to long term gavage feeding include oral stimulation hypersensitivity, esophageal inflammation, pharyngeal desensitization, gastroesophageal reflux and vomiting $(2,3)$. Therefore, prolonged gavage feeding must be avoided.

Preterm infants begin sucking feeds when they are mature enough to co-ordinate sucking and swallowing, which occurs at around 32 to 34 weeks of gestation (4). The alternative oral feeding methods before this time include bottle feeding, cup feeding, spoon feeding, syringe feeding, finger feeding, the use of a lactation aid at the breast or slow-paced bottle feeding. It is important to support the mother in understanding the possible benefits and risks associated with the use of an alternative feeding method. The WHO recommends low birth weight (LBW) infants who need to be fed by an alternative oral feeding method should be fed by cup (or palladai, which is a cup with a beak) or spoon (5). "Nipple confusion" is the term commonly applied to a breastfeeding problem hypothesized to result from the mechanical differences between sucking at the breast and sucking on a bottle nipple $(6,7)$. Scientific studies of nipple confusion are lacking, but there are studies indicating that the mechanics of bottle-feeding and breastfeeding differ (7). Bottle-feeding is not recommended for breastfed preterm infants in order to avoid artificial nipples. Unfortunately, preterm infants, even those who are breastfed at hospital discharge, are often weaned soon after. Many studies have been conducted to evaluate the effects of cup feeding during transition on breastfeeding rates of term infants. No data exists related to syringe use regarding its relevance for feeding preterm infants.

The aim of this study was to compare the effects of syringe and bottle feeding on the passing period to oral feeding, time at passing to full breastfeeding, time discharge of newborns, body weight at discharge and daily weight gain in very LBW preterm infants.

\section{Materials and Methods}

This study was conducted at a level 2 neonatal intensive care unit (NICU) between January 2013 and January 2015 in the Zekai Tahir Burak Maternity Teaching Hospital in a comparative and descriptive clinical study pattern. The research group was composed of preterm infants who received treatment and clinical care during the study period and who met the study criteria. The study was approved by the Zekai Tahir Burak Women's Health Training and Research Hospital Ethics Committee (approval number: 22/2018) and informed parental consent was obtained for all infants.

Eligibility criteria included body weight less than or equal to $1.500 \mathrm{~g}$, gestational age younger than 32 weeks, growth parameters appropriate for gestational age, tolerating at least $100 \mathrm{kcals} / \mathrm{kg} / \mathrm{d}$ oragastric tube feeding at the recruitment to the study, and a stable clinical condition. The exclusion criteria included: grades 3 and 4 periventricular hemorrhage (8); clinical instability at the time or during the study, such as the presence of necrotizing enterocolitis (9) sepsis, bronchopulmonary dysplasia (10), or other respiratory or hemodynamic clinical instabilities; Apgar score $<5$ at the $5^{\text {th }}$ minute; or presence of genetic syndromes, neurological disorders, or congenital malformation of the head and neck, or of the central nervous system. The research was conducted with 103 premature infants of whom 47 were in the syringe-fed group (SG) and 56 in the bottle-fed group (BG). Start trophic and low-volume gavage feeding within 24 hrs of life. The transition from gavage to oral feeding started when the preterm infants reached at least 32 postconceptional weeks and were tolerating at least $100 \mathrm{kcals} / \mathrm{kg} / \mathrm{d}$ oragastric tube feeding. The infants were started with one oral feeding per day, and the number of daily oral feedings was increased gradually, depending on how infants tolerated each additional feeding. Each infant's feeding goal was established by their NICU medical team, ranging from 140 to $180 \mathrm{~mL} / \mathrm{kg} / \mathrm{d}$, and was divided into 8 to 12 portions according to the infant's weight. We implimented a schedule that babies weighing $\geq 1.500 \mathrm{~g}$ be fed three times hourly and those weighing $<1.500 \mathrm{~g}$ twice hourly. Breastfeeding was started when the preterm infant exhibited signs of physiologic stability and evidence of early feeding behaviors such as rooting, strong sucking on the pacifier and hand-to-mouth behaviors.

Syringe Fed Group: These infants were fed first with a syringe in the oral feeding period. The syringe was placed in the middle of the baby's tongue, gently touching the baby's palate to promote sucking of the syringe. Similar to the finger feeding technique, the nurse gently applied pressure with the syringe while stroking the mouth, gums, tongue and palate. Syringe feeding is shown in Figure 1. The nurse

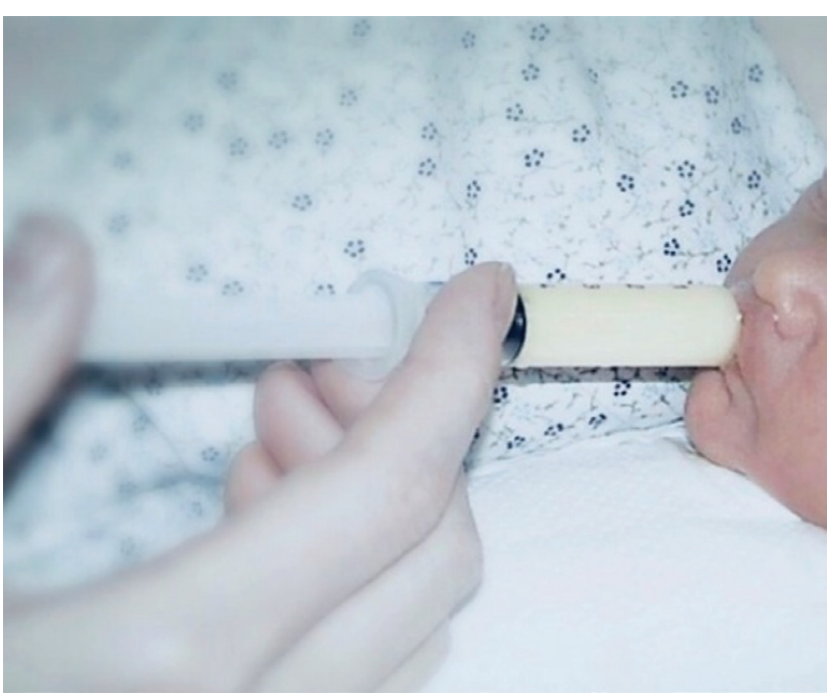

Figure 1. Syringe feeding baby 
then held the baby in an upright position and gently gave no more than 3-5 milliliters of milk or formula at a time into the baby's mouth, the milk being between the gum and cheek or on the tongue of the infant. The baby was then allowed to swallow before giving another 3-5 milliliters of milk or formula until the feed was ended. Our priority was to feed infants with breast milk. However, some infants who did not have a sufficient quantity of breastmilk were fed with formula.

Bottle-Fed Group: These infants were first fed with a bottle during oral feeding. The nipple used was NUK ${ }^{\circledR}$ for milk as it limits the milk flow during sucking.

Vital signs (temperature, respiratory rate, pulse, oxygen saturation) were monitored regularly according to NICU medical procedures. The time required for feeding, weight gain, and episodes of gastro-intestinal intolerance symptoms, and daily weight gain and duration of hospitalization were recorded in the patient's file. The NUK nipple selected for premature newborns was chosen for its anatomic shape and because it was developed for premature newborns who weigh less than $1.750 \mathrm{~g}$. It is made of flexible latex with a very small hole, which forces the preterm infants to compress it to extract milk.

Upon discharge of the infant from the hospital, the mother was counseled with regard to breastfeeding. If the mother's milk supply was inadequate, guidelines were provided for complementation with milk formula according to the feeding routine proposed by the NICU.
Primary outcomes were time at transition from gavage feeding to full oral feeding, time at transition from tube to breastfeeding and length of hospital stay. Secondary outcomes were body weight at discharge (g), daily body weight gain (g/days) and gastro-intestinal intolerance symptoms during the transition period.

\section{Statistical Analysis}

Data was analyzed using IBM SPSS Statistics 21.0 (SPSS, Inc, Chicago, IL, USA) statistical package program and statistical significance was set at $p<0.05$. A descriptive analysis of the demographic and clinical characteristics of the patients was conducted. Student's t-test for parametric data or Mann-Whitney $U$ test for non-parametric data were used for comparison of variables between the two groups. Chi-square test was used to compare ratios between the two groups.

\section{Results}

One hundred and three infants were included in the intention to treat analysis ( $S G, n=47 ; B G, n=56$ ). Characteristics of the participants, including both maternal and neonatal characteristics, were balanced between the groups (Table I). Mean gestational ages were $29.82 \pm 2.03$ vs $28.18 \pm 1.56$ weeks $(p=0.24)$, and the mean birth weights were $1,150.31 \pm 232.29$ vs $1,016.87 \pm 186.64 \mathrm{~g}(\mathrm{p}=0.72)$ in the SC and BG groups, respectively. One hundred and three infants with gavage feeding, ranging from 26 to 32 weeks gestational

Table I. Comparison of baseline characteristics of the study population

\begin{tabular}{|l|l|l|l|}
\hline Parameters & Syringe group, $\mathbf{n = 4 7}$ & Bottle group, $\mathbf{n = 5 6}$ & $\mathbf{p}$ value \\
\hline Maternal age, mean \pm standard deviation, weeks & $28.72 \pm 5.8$ & $27.62 \pm 6,1$ & 0.35 \\
\hline Gestational age, mean \pm standard deviation, weeks & $29.82 \pm 2.03$ & $28.18 \pm 1.56$ & 0.24 \\
\hline Birth weight, mean \pm standard deviation, $\mathrm{g}$ & $1150.31 \pm 232.29$ & $1016.87 \pm 186.64$ & 0.72 \\
\hline Caesarean delivery, $\mathrm{n}(\%)$ & $41(45.6)$ & $49(54.4)$ & 0.82 \\
\hline Female, $\mathrm{n}(\%)$ & $24(47.1)$ & $27(52.9)$ & 0.84 \\
\hline Antenatal steroids, $\mathrm{n}(\%)$ & $29(41.4)$ & $41(58.6)$ & 0.28 \\
\hline Premature rupture of membrane >18 hours, $\mathrm{n}(\%)$ & $6(31.6)$ & 0,05 \\
\hline Apgar score at 1 min, median (minimum-maximum) & $13(68.4)$ & $6(4-8)$ & 0.25 \\
\hline Apgar score at 5 min, median (minimum-maximum) & $6(3-7)$ & $8(5-9)$ & 0.16 \\
\hline Small for gestational age, $\mathrm{n}(\%)$ & $8(5-9)$ & $10(55.6)$ & 1 \\
\hline Maternal preeclampsia, $\mathrm{n}(\%)$ & $8(44.4)$ & $11(45.8)$ & 0.35 \\
\hline Patent ductus arteriosus, $\mathrm{n}(\%)$ & $13(54.2)$ & $17(54.8)$ & 1 \\
\hline Necrotizing Enterocolitis, stage $\geq 2, \mathrm{n}(\%)$ & $14(45.2)$ & - & $20.55 \pm 12.75$ \\
\hline Time to full enteral feeds, mean \pm standard deviation & 3 & $26(60.5)$ & 0.05 \\
\hline LNS, (clinically suspected), $\mathrm{n}(\%)$ & $16.65 \pm 9.09$ & $8(44.4)$ & 0.39 \\
\hline LNS, (culture proven), $\mathrm{n}(\%)$ & $17(39.5)$ & $10(55.6)$ & 0.32 \\
\hline
\end{tabular}

LNS: Late neonatal sepsis; mean \pm standard deviation 
age, achieved a full oral feeding start time, which for syringe-fed preterm infants had a mean of $40.45 \pm 19.50$ days and for bottle-fed infants had a mean of $53.81 \pm 16.97$ days ( $p>0.05$ ). The comparison of syringe and bottle groups is presented in Table II. However, there were significant differences between the groups for transition time to full breastfeeding and time to discharge $(p<0.05)$. There were no significant differences in time to reach birth weight, body weight at discharge, body weight gain (g/day) and time at transition from gavage feeding to oral feeding. The time to transition to full breastfeeding $(42.54 \pm 21.21$ days) and time to discharge $(54.48 \pm 26.92$ days) in the SG was significantly shorter than the BC $(50.45 \pm 15.95 ; 67.21 \pm 22.07$, days, respectively) $(p<0.05)$. There were no significant differences in the prevalence of breastfeeding for preterm infants with syringe feeding compared to bottle feeding at six months after discharge (Table II).

\section{Discussion}

Avoidance of bottles in healthy breastfeeding term infants is a basic belief for successful breastfeeding, and hospitals that avoid bottles have significantly higher breastfeeding success rates (11). However, the effect of the "no bottles" technique on breastfeeding success in preterm infants is not fully proven. To do so, there are several methods of providing enteral nutrition to premature infants without using a bottle $(12,13)$. The most commonly used method of feeding preterms other than bottles is cup-feeding. As far as we know, there are no reports on a syringe feeding method for preterm infants. The purpose of this study was to compare the effect of bottle and syringe feeding on the timing of initiating oral feeding and time for transition to full breastfeeding. There were significant differences between the groups in time for transition to breastfeeding, time for transition to full breastfeeding and time to discharge. However, there were no significant differences in time to transition from gavage feeding to oral feeding. Aloysius and Hickson (14) showed administration of oral supplements by cup at a time earlier than infants would be able to co-ordinate sucking, swallowing and breathing for bottle-feeding. Additionally, previous studies reported that cup-fed infants demonstrated significantly more mature breast feeding behaviors when compared to bottle-fed infants (13-15). Dalal et al. (16) found rapid improvement in feeding performance with increasing experience and maturity with paladai feeding. Additionally, they suggested paladai or feeding bottles could be equally safe methods of feeding for hospitalized preterm neonates. The Cochrane review found that cup feeding did not result in longer maintenance of breastfeeding beyond discharge (17). Another review suggested that using a cup instead of a bottle increases the extent and duration of breastfeeding in preterm infants (13). Due to these conflicting results with regard to breastfeeding rates, additional work is needed before the tube alone approach is suggested.

A systematic review by Arvedson et al. (18) also showed positive effects of oromotor interventions for improvement in feeding/swallowing physiology variables. In most infants, the coordination between swallowing and breathing develops to a reasonable level to allow full oral feeding by 32-34 weeks post-conceptional age (19). Feeding performance including coordination of swallowing and breathing improves within a few days of starting paladai feeds thereby helping in early transfer of these infants to their mothers (17).

There are several advantages of syringe feeding in our opinion. First, syringe feeding encourages coordinated breathing, sucking and swallowing in preterm infants. Secondly, syringe feeding allows the infant to control the amount and rate of feeding. Third, syringe feeding results in a positive parental involvement so that mothers

Table II. Clinical profile of neonates

\begin{tabular}{|c|c|c|c|}
\hline Parameters & $\begin{array}{l}\text { Syringe group, } \\
(n=47)\end{array}$ & $\begin{array}{l}\text { Bottle group, } \\
(n=56)\end{array}$ & $\mathrm{p}$ value \\
\hline Full oral started (postnatal age in days), mean \pm standard deviation & $40.45 \pm 19.50$ & $53.81 \pm 16.97$ & 0.17 \\
\hline Time for transition to breastfeeding (postnatal age in days), mean \pm standard deviation & $42.54 \pm 21.21$ & $50.45 \pm 15.95$ & 0.04 \\
\hline At discharge days (postnatal age), mean \pm standard deviation & $54.48 \pm 26.92$ & $67.21 \pm 22.07$ & 0.01 \\
\hline Time to reach birth weight, day, mean \pm standard deviation & $13 \pm 5.57$ & $15.10 \pm 5.10$ & 0.05 \\
\hline At discharge weight $(\mathrm{g})$, mean \pm standard deviation & $2027.29 \pm 357.3$ & $2050.23 \pm 434.8$ & 0.77 \\
\hline Body weight gain, g/day, mean \pm standard deviation & $22.11 \pm 12.61$ & $20.19 \pm 7.20$ & 0.33 \\
\hline Breastfeeding infants, $\mathrm{n}(\%)$ & $46(46.5)$ & $53(53.5)$ & 0.38 \\
\hline Gastro-intestinal motility disturbance, $\mathrm{n}(\%)$ & $14(38.9)$ & $22(61.1)$ & 0.40 \\
\hline Abdominal distension, $\mathrm{n}(\%)$ & $14(40)$ & $21(60)$ & 0.53 \\
\hline Vomiting, n (\%) & $13(48.1)$ & $14(51.9)$ & 0.82 \\
\hline
\end{tabular}


have early positive body/eye contact resulting in the development of a positive parent-neonate attachment. Fifth, syringe feeding avoids nipple confusion caused by bottle-feeding. Sixth, since disposable syringes can be used, it is less risky in terms of infection than other alternative methods for preterm infants. Complication rates have been reported to be lower during the initiation of feeding in preterm infants. Commonly reported complications with syringe feeding include aspiration and oral thrush. There were no complications in the SG during the hospital stay in our study. Bottle feeding has been associated with the development of increased risk of bacterial contamination resulting in diarrhea and infections both in developed and developing countries $(16,6,18)$. There were no complications in the BC during the hospital stay in our study.

\section{Conclusion}

Syringe-fed infants had a shorter time for transition from gavage feeding to oral feeding compared to bottle-fed infants and they had a shorter hospital stay. We therefore suggest supporting the Baby Friendly Hospital Initiative recommendations by using syringe feeding and avoiding bottle-feeding when providing supplementation to gavage feeding for preterm infants.

\section{Ethics}

Ethics Committee Approval: Zekai Tahir Burak Women's Health Training and Research Hospital Ethics Committee (approval number: 22/2018).

Informed Consent: Informed parental consent was obtained for all infants.

Peer-review: Externally peer-reviewed.

\section{Authorship Contributions}

Surgical and Medical Practices: B.S., F.E.C., Ş.S.O., Concept: B.S., Design: B.S., Data Collection or Processing: B.S., M.B., N.O., G.K.Ş., Analysis or Interpretation: F.E.C., Ş.S.O., Literature Search: B.S., M.B., N.O., G.K.Ş., N.U., Writing: B.S.

Conflict of Interest: The authors have no conflicts of interest relevant to this article to disclose.

Financial Disclosure: The authors have no financial relationships relevant to this article to disclose.

\section{References}

1. Thomas JA. A parent's guide to bottle feeding your premature baby. Adv Neonatal Care 2007;319-20.

2. Strudwick S. Gastro-oesophageal reflux and feeding: the speech and language therapist's perspective. Int I Pediatr Otorhinolaryngol 2003;67(Suppl 1):101-2.

3. Mason SJ, Harris G, Blissett J. Tube feeding in infancy: Implications for the development of normal eating and drinking skills. Dysphagia 2005;20:46-61.

4. Lemons IA, Bauer CR, Oh W, et al. Very low birth weight outcomes of the National Institute of Child health and human development neonatal research network, January 1995 through December 1996. NICHD Neonatal Research Network. Pediatrics 2001;107:1.

5. Lopoz CP, Silva RG. Alternative feeding methods for premature newborn infants. Rev Paul Pediatr 2012;30:278-82.

6. Howard CR, Howard FM, Lanphear B, et al. Randomized clinical trial of pacifier use and bottle-feeding or cupfeeding and their effect on breastfeeding. Pediatrics 2003;111:511-8.

7. Dowling DA, Meier PP, DiFiore JM, Blatz MA, Martin RJ. Cupfeeding for preterm infants: mechanics and safety. I Hum Lact 2002;18:13-20.

8. Papille LA, Burstein J, Burstein R, Koffler $\mathrm{H}$. Incidence and evolution of subependymal and intraventricular hemorrhage: a study of infants with birth weights less than $1500 \mathrm{~g}$. I Pediatr 1978;92:529-34.

9. Bell MJ, Ternberg IL, Feigin RD, et al. Neonatal necrotizing enterocolitis. Therapeutic decisions based upon clinical staging. Ann Surg 1978;187:1-7.

10. Jobe AH, Bancalari E. Bronchopulmonary dysplasia. Am J Respir Care Med 2001;163:1723-9.

11. Nye C. Transitioning premature infants from gavage to breast. Neonatal Netw 2008;27:7-13.

12. Rocha $A D$, Lucena $S L$, Costa $A M$, Moreira MEL. Cup or bottle use and their effect on exclusive breast feeding rates in preterm infants: a randomized clinical trial. Acad J Ped Neonatol 2017:3.

13. Collins $C T$, Gillis J, McPhee A), Suganuma $H$, Makrides $M$. Avoidance of bottles during the establishment of breast feeds in preterm infants. Cochrane Database Syst Rev 2016;10:CD005252.

14. Aloysius A, Hickson M. Evaluation of paladai cup feeding in breast-fed preterm infants compared with bottle feeding. Early Hum Dev 2007;83:619-21.

15. Abouelfettoh AM, Dowling DA, Dabash SA, Elguindy SR, Seoud IA. Cup versus bottle feeding for hospitalized late preterm infants in Egypt: a quasi-experimental study. Int Breastfeed I 2008;3:27.

16. Dalal SS, Mishra S, Agarwal R, Deorari AK, Paul VK, Sankar MJ. Feeding behaviour and performance of preterm neonates on Paladai feeding. Acta Paediatr 2013;102:147-52.

17. Hanif HM. Trends in breastfeeding and complementary feeding practices in Pakistan, 1990-2007. Int Breastfeed I 2011;6:15.

18. Arvedson J, Clark H, Lazarus C, Schooling T, Frymark T. Evidencebased systematic review: effects of oral motor interventions on feeding and swallowing in preterm infants. Am / Speech Lang Pathol 2010;19:321-40.

19. Turkyilmaz C, Bilgen H, Kultursay N. Guide to the feeding of premature and patient babies. Turkish Neonatology Association 2018:34-6. 